University of Wollongong

Research Online

The Future of Learning Design Conference

Program

Dec 10th, 10:00 AM - 10:45 AM

\title{
Understanding the design context for Australian university teachers: Implications for the future of learning design
}

\author{
S. Bennett \\ University of Wollongong, sbennett@uow.edu.au \\ Lisa Kosta \\ University of Wollongong, lkosta@uow.edu.au \\ S. Agostinho \\ University of Wollongong, shirleya@uow.edu.au \\ L. Lockyer \\ University of Wollongong, lori.lockyer@gmail.com \\ J. Jones \\ University of Wollongong, jenjones@uow.edu.au
}

See next page for additional authors

Follow this and additional works at: https://ro.uow.edu.au/fld

Bennett, S.; Kosta, Lisa; Agostinho, S.; Lockyer, L.; Jones, J.; and Harper, B., "Understanding the design context for Australian university teachers: Implications for the future of learning design" (2009). The Future of Learning Design Conference. 1.

https://ro.uow.edu.au/fld/09/Program/1

Research Online is the open access institutional repository for the University of Wollongong. For further information contact the UOW Library: research-pubs@uow.edu.au 


\section{Description}

Based on the premise that support for university teachers in designing their units will improve teaching and ultimately improve the quality of student learning outcomes, recent interest in the development of tools and strategies has gained momentum. This paper reports on a study that has examined the contexts in which Australian university teachers design in order to understand what role design support tools and strategies could play. It appears that Australian university teachers can exercise a high degree of choice in terms of design, indicating that there may be opportunities for teachers to consider using reusable learning designs.

\section{Location}

233.G01

\section{Presenter Information}

S. Bennett, Lisa Kosta, S. Agostinho, L. Lockyer, J. Jones, and B. Harper 


\title{
Understanding the design context for Australian university teachers: Implications for the future of learning design
}

\author{
Sue Bennett, Lisa Kosta, Shirley Agostinho, Lori Lockyer, Jennifer Jones and Barry Harper \\ University of Wollongong
}

\begin{abstract}
Based on the premise that support for university teachers in designing their units will improve teaching and ultimately improve the quality of student learning outcomes, recent interest in the development of tools and strategies has gained momentum. This paper reports on a study that has examined the contexts in which Australian university teachers design in order to understand what role design support tools and strategies could play. It appears that Australian university teachers can exercise a high degree of choice in terms of design, indicating that there may be opportunities for teachers to consider using reusable learning designs.
\end{abstract}

\section{Introduction}

Recent interest in the development of tools and strategies to support university teachers design their units is based on the premise that such supports will improve teaching and ultimately improve the quality of student learning outcomes. This body of work includes a varied set of related approaches such as online collections that enable teachers to publish, search for and comment on learning and teaching ideas. Examples include the Technology-Supported Learning Database (http://aragorn.scca.ecu.edu.au/tsldb/), the Phoebe Pedagogic Planner (http://phoebeapp.conted.ox.ac.uk/) and Cloudworks (http://cloudworks.open.ac.uk/). Work is also advancing systematic formalisms for descriptions, such as pedagogical patterns (e.g., http://patternlanguagenetwork.org/about/) or learning design sequences (e.g., http://www.learningdesigns.uow.edu.au/).

Complementing these efforts are developments focused on tools to support the design process, including:

- Authoring systems for constructing and delivering sequences of learning activities (e.g., $\mathrm{http}: / / \mathrm{www}$. lamsinternational.com/)

- Tools for analysis and planning (e.g., http://www.wle.org.uk/d4l/; http://www.phoebe.ox.ac.uk/)

- Simple authoring tools for customising digital resources (e.g., http://www.glomaker.org/)

- Software for creating visual representations of their educational designs (e.g., $\mathrm{http}: / / \mathrm{kn}$. open.ac.uk/public/workspace.cfm?wpid=8690)

- Support systems providing guidance for adapting existing design ideas (Bennett et al., 2007; Hernández-Leo et al., 2006)

- Tools for working with technical specifications (http://www.tencompetence.org/ldauthor/; http://edutechwiki.unige.ch/en/Prolix_graphical_learning_modeller).

All of these efforts assume that:

- University teachers have a need to adopt such supports;

- These tools and strategies can be designed in such a way as to be truly useful in the process of teaching planning and preparation; and 
- Support tools will enable teachers to adopt new effective models by exposing them to new ideas and support their design processes. Key to this process is enabling teachers to learn about new pedagogies during the process of design so that they adapt ideas to their contexts.

There is little empirical evidence that confirms or disputes these assumptions. An important aspect that requires examination is teachers' contextual pre-conditions to using such supports. One important factor in this discourse is understanding the extent to which university teachers are actually able to make design decisions. Put simply, if teachers are not able to make decisions about what and how they teach, what types of assessment they offer or what types of learning supports they can make available to students, then the necessary pre-conditions for using design support tools do not exist. Without a degree of freedom to customise a pattern or a learning design, then new ways of teaching (and hence learning) cannot be supported through the use of abovementioned support tools/processes. The investigation reported in this paper sought to address this gap by providing insights into the contexts in which Australian university teachers design in order to understand what role support tools can play.

\section{Methodology}

Data was collected through semi-structured interviews with 30 university teachers. Participants were purposively sampled from a larger group of volunteers who responded to an invitation distributed through the electronic mailing lists of relevant professional associations in Australia (including HERDSA, ascilite, ODLAA and AARE). The criteria for selection ensured that perspectives were collected for university teachers across a range of discipline areas (11 participants from the Sciences, 10 from the Arts and Humanities, and 9 from the Professions), and with a range of teaching experience (including both face-to-face and online delivery). These decisions were made on the basis of a series of preliminary questions to which volunteers responded when accepting the invitation to participate.

Of the 30 participants, 14 taught at undergraduate level only, 15 at both undergraduate and postgraduate, and 1 at postgraduate only. The majority of participants taught units ${ }^{1}$ that combined face-to-face and online modes (22), 3 taught units that combined online and mail-out distance education, 4 taught only face-to-face and 1 taught only online.

The participants were asked about their teaching approach, the context in which they worked, their approach to designing their teaching, the key influences on their design practices and what supports they accessed and/or used to help them. The interview protocol was informed by an initial literature review of research about teachers' design practices and was reviewed by the six-member research team. The duration of the interviews was between 50 and 90 minutes, and due to graphical location, most of the interviews were conducted by telephone. The interviews were audio-recorded, transcribed and analysed by a six-member research team. The analysis comprised developing a coding framework which was derived from the interview questions and themes that emerged from the interview transcripts. Each interview was double-coded using the coding framework by two researchers. Discrepancies in coding were used to refine the definitions of categories until interrater agreement was achievedThe findings reported in this paper focus on the data that provided an understanding of the context in which teachers do their design work.

\footnotetext{
${ }^{1}$ For consistency the term 'unit' is used to describe a component of a programme of study that results in a qualification.

'Course' is used to describe the overall programme.
} 


\section{Results}

The following themes that surfaced from the interview data, illustrate the context in which teachers conducted their design work.

\section{Set Curriculum}

The processes by which the curriculum for any course is determined is an important factor in understanding the degree of autonomy university teachers have in deciding what and how they teach. When asked about how the curriculum was set, responses ranged from those who worked within an institution or faculty with a pre-defined - 'set' curriculum through to those who had full control of over what and how they taught.

Eighteen (18) participants indicated that they worked within a set curriculum, though the definition of what this meant in practice varied. Fourteen (14) respondents described a set curriculum as containing any combination of pre-determined outcomes, content and assessment guidelines. Generally a set curriculum offered an overall structure with freedom to move within it, as illustrated by the following two excerpts:

We stick to the accredited document units as they were accredited in terms of certain number of assessment tasks and the nature of the content, the number of outcomes, the nature of the outcomes and etc. (Paul, Professions)

I was presented with unit outlines that had already been approved for the units I was going to take over. And so within that unit outline, I had to cover that content material but the way that I delivered that or the things I added to that were completely at my discretion. (Debbie, Sciences)

For two participants whose curriculum was set at an institutional level, curriculum content and objectives were heavily influenced by industry and accreditation requirements. For example, in a course on mining, the institution liased with industry representatives to plan curriculum components. However, the faculty had ultimate control of course planning and aimed to work within a "national approach to mining education" (Craig, Professions). In a nursing example, one participant described a "McDonald-ised curriculum" which was required to satisfy registration across three states and a territory (Bill, Professions).

There were twelve participants who indicated that they were not guided by a set curriculum at all. Typical comments included:

We all have complete freedom to create our own curriculum. (Christine, Arts)

It's entirely up to me, there's no national curriculum, there's no professional framework, it's very idiosyncratic and that's characteristic of my discipline area... we teach what interests us provided we stay within the general area. (Kerrie, Arts)

In one case, the reason for the lack of a set curriculum was the dynamic nature of the discipline and the need for units to be changed and updated regularly:

So the curriculum's not hard core set because as technology changes we need to keep up to date with technology. (Deidre, Sciences) 
Some participants pointed out that, regardless of whether there was a set curriculum or complete freedom, it was important to discuss any changes or additions with other teachers in the course because changes in one unit may affect another. This occurred either as an incidental individual action, or through a structured team approach, for example:

There's a lot of informal negotiation about content between staff because we obviously rotate our teaching roles. (Shane, Arts)

In terms of curriculum development no it's entirely up to us to determine what we want in there but we do that as a result of our team meetings. (Debbie, Sciences)

\section{Teaching the same units every year}

Another feature of the context that may influence a university teacher's capacity to take on a new design is whether they teach the same units every year, and thus have an opportunity to refine the design over time. Eighteen (18) participants stated that they taught the same units each year:

Here there's a [belief] that it's much more efficient if you do teach a [unit] for some period of time. (Kathleen, Professions)

I teach the same [units] each year and I enjoy it. (Trent, Arts)

Another eight participants indicated that the units they taught varied. This was generally due to other staff taking leave, different units being made available due to demand, new units being developed, or units being discontinued due to lack of interest or change in curriculum structure. Typical comments included:

The only changes that would occur otherwise for me would depend on who's on leave and whether there is a spot to be filled somewhere else. (Gloria, Sciences)

We rotate them a bit depending on who's on leave, who's on sabbatical, what [units] we want to offer that particular year. (Christine, Arts)

Two participants explained that core units were always part of their teaching loads:

Some units, they vary but the core [units], I've been teaching them for the last four, five years. (Cameron, Professions)

Smaller, more specialised units were often offered on a rotating basis depending on which other units were offered and who was available to teach them. For example, one participant spoke about teaching different units each year, though maintained a cyclical approach to this.

I create them all moving around, depending on what other people are offering or what I thought hasn't been taught in a while, but usually within a three-year cycle I teach all my [units]. (Julie, Arts) 


\section{Frequency of new unit design}

In addition to having opportunities to redesign units that are taught on an ongoing basis, the need to design new units is also a feature of university teachers' design work. Five participants indicated that they had never been involved in the development of a new unit, but for the remaining twentyfive participants, the frequency of new unit design ranged from "only once" to "every semester". Comments included:

I guess we [design a new unit] every time we have a new curriculum coming through, which is generally about every four to five years. (Belinda, Sciences)

On an average, I might say one per year. (Cameron, Professions)

At the moment I've designed an entirely new [unit] every semester that I've taught and that will be true for the next year as well. (Heidi, Arts)

When I first started I designed all of them. (Katrina, Arts)

\section{Frequency of unit redesign}

Participants were asked about how often they redesigned a unit, rather than designing it from scratch. The purpose of this question was to ascertain how often micro unit design work occurs. This question provoked a range of responses from participants with 3 indicating they seldom redesigned a unit, 14 stating that it was every time the unit was offered (generally every semester or every year), and 9 participants found themselves to be constantly redesigning or 'tweaking' their units. Typical comments included:

Fairly rarely. (Richard, Sciences)

Minor revisions every year. (Kurt, Sciences)

I'm very fussy, which is probably my downfall so I'll commonly just tweak things as such as I don't think exactly what I wanted was right. (Darren, Sciences)

Redesign sometimes included a process of meetings with colleagues, which were specifically held for the purpose of reviewing (major and minor reviews) and adjusting units:

We meet twice a year in July and December and review the progress of those [units] in the previous semester. (Craig, Professions)

We would probably go through every semester after each semester. We have a planning session to debrief, how did it go, what's missing, how do we tweak this, where do we have to move it, what's the next step in the developmental process? (Debbie, Sciences)

Participants indicated that redesign was mainly engaged in to continually improve a unit, to keep up to date and meet industry needs, or for the purposes of personalising a unit when taking over from another teacher. 


\section{Team and individual planning}

Eighteen participants were involved in both team and individual planning. Illustrative comments included:

It will vary... we tend to be responsible for a particular studio class, however we might share the lecture series. (George, Arts)

For example our first year unit, which some of it's team taught, we definitely design the tutorial program and the different modules within the unit... we design together to make sure that it flows and meets with the teaching objective. So we definitely collaborate, but in units where I teach on my own, I actually don't tend to collaborate as much, but I'd ask for advice from my colleagues" (Katrina, Arts)

Seven conducted their planning as a purely individual activity. Some comments were:

In terms of the intellectual content, no you don't put it to colleagues at all. This is completely individualised creation of [units] here. (Kirk, Arts)

You tend to [plan individually] in science. You have ownership of your own content. (Terence, Sciences)

Five indicated that all of their planning was done as a team. For those who always or sometimes planned in a team, two different approaches were evident. There were those who planned in a structured team approach where meetings were scheduled, and those who took an unstructured team approach where collaboration was more incidental. Examples of unstructured team planning included:

I tend to work alone... because it's an area I'm so unfamiliar with [it]. I actually got a colleague who knows my area to check my lectures. (Darren, Sciences)

And for me to make significant changes, I would be definitely talking to most of the rest of the academics in the school, because it feeds to their second-year [units]. (Gloria, Sciences)

I tend to talk it through with the tutors but I tend to work it myself. (Lily, Professions)

I do an initial draft myself, and then send it out to colleagues to provide me with feedback. (Michelle, Professions)

In cases when a structured approach to team planning was used, some participants engaged in a team effort whereby the whole unit was planned together right down to the finest detail. Others would plan an overarching curriculum together, go away and work on it individually and, in some cases, reconvene to discuss their design. For some, the need for a team approach was seen as necessary when different teachers where delivering the same unit across different campuses. The following excerpts illustrated the range of approaches:

In terms of curriculum development, it's entirely up to us to determine what we want in there, but we do that as a result of our team meetings, of a strategic plan as to where we see the degree evolving, what it is that we want to bring into this, why we think it's important 
and situated on top of a very detailed, well articulated theoretical framework that underpins the entire degree structure. (Debbie, Sciences)

Yes, we have stream-oriented teams, [and] we have another team that's looking after core units and then within that each unit will have a team of people particularly in the development stages. So teams could be anywhere from two to four or five people. (Joyce, Professions)

We called it a 'course advisory group'. Industry people, people from our teaching and learning area, people from our knowledge media area and the academics that were going to be teaching the unit. (Patricia, Professions)

One participant also indicated the perceived benefits of and a desire to move towards a team teaching approach:

We certainly would like to move towards a more sort of organised team approach to some courses. And the reason we would like to do that is that I think it's good to have another person making decisions with you and it's good to work with other people where there's a division of labour. And it's good to share responsibilities for the hard parts of teaching, dealing with plagiarism cases... I prefer to do it in a team, I think you end up with a much better course. (Shane, Arts)

\section{Institutional features and requirements}

Other factors influencing teachers' freedom to design are structural features of their institutions and the requirements institutions made. Participants referred to common types of policies developed in most tertiary education environments such as: assessment policies; evidence of graduate attributes; planning policies in terms of the development of unit objectives, and unit outline documents; and semester length and contact hours. These questions drew responses such as:

I suppose with respect to policy, the main thing is that you check the various boxes and you know that you've got to have $30 \%$ of your content, $30 \%$ of assessment done by the end of Week 5. (Gloria, Sciences)

We are obliged by our university policy to put certain things online full stop... It is specified in the strategic plan and in the online teaching and learning policy that we have to have an instructor moderated discussion board, we have to have a student discussion board on there, we have to have all of our resources on there and linked if possible. (Bill, Professions)

You've got to look at what we call 'embedding graduate attributes' in the course and that means what people are really looking for out in the big wide world from graduates. (Kathleen, Professions)

All but two participants indicated that such policies existed, and were somewhat influential in the design process, but did not place great restrictions on what they could design. Typical comments included:

There are (policies), and how much I know and actually pay attention to them is probably another question. (Christine, Arts) 
We have those and you just have to keep them in mind. (Kathleen, Professions)

They tend to be more in this guideline capacity rather than actually enforced. (Katrina, Arts)

\section{Discussion}

The findings highlight that the context in which Australian university teachers design has particular characteristics. There appears to be significant levels of flexibility and freedom for university teachers in how they design and deliver their units. Forty percent of participants taught in a context where there was no set curriculum thus enabling them the freedom and autonomy to deliver units according to their own design decisions. More than half of the participants $(60 \%)$ taught within a set curriculum in that there were some preset guidelines to follow such as predetermined learning outcomes, required content to cover and assessment policies to follow. Yet, the majority of these teachers explained that there was flexibility within this structure in terms of how they delivered their units.

There is both continuity and variation in what teachers teach and continuity was influenced by the nature of the unit, that is, whether it is a core unit with large enrolments or a more specialised unit with a smaller cohort. The majority $(60 \%)$ of participants stated they taught the same units each year. Almost a third of participants stated that the units they taught varied. This suggests a context in which there may be opportunities to iteratively develop a unit taught over a period of time, but also to teach new units.

Teachers are regularly involved in both the design and redesign of new units. A majority of participants had been involved in designing a unit from scratch and most stated they 'tweaked' units each time they taught them to continually improve them. These activities demonstrate the extent to which varying levels of design activity are a routine part of academic teaching.

Teachers engage in both team and individual unit planning. Seven respondents always worked alone when doing unit planning, but the majority were involved in both team and individual planning. Team planning often occurred at a course level, with individuals often left to design their own subjects within an agreed overall programme.

Institutional policies on unit requirements such as assessment policies, planning policies, length of semester were reported as influential in the design process, but the participants in this study suggested that these were not overly restrictive.

These findings suggest that the Australian university context may possess the necessary preconditions for using design support tools, as teachers do have reasonable scope to make important decisions about what and how they teach. This, however, needs further investigation as this study is limited by the relative small sample size. Whilst beneficial to glean insight into teachers' design practices, data from 30 participants limits the ability to make generalised conclusions. The research team is considering developing the interview protocol into an online survey in order to collect a larger sample size across an international context.

In terms of the implications for the future of learning design, this study represents a necessary path of research as espoused by recent literature about learning design (eg., Donald, Blake, Girault, Datt, 
\& Ramsay, 2009), as it is important to understand to context in which teachers design in order to offer them the most effective support tools to assist them in this process.

\section{Conclusion}

This paper has reported a study that has examined the contexts in which Australian university teachers design in order to understand what role design support tools can play. Thirty Australian university teachers were interviewed about their design practice and the findings suggest that Australian university teachers can exercise a high degree of choice in terms of design, and therefore there may be opportunities for teachers to consider using reusable learning designs. This study sought to advance knowledge about learning design by investigating teachers' design practices and the influences that result in these practices.

\section{References}

Bennett, S. Agostinho, S., \& Lockyer, L. (2005). Reusable learning designs in university education. In T. C. Montgomerie \& J. R. Parker (Eds.), Proceedings of the IASTED International Conference on Education and Technology (pp.102-106). Anaheim, CA: ACTA Press.

Bennett, S., Agostinho, S., Lockyer, L., Kosta, L., Jones, J., Koper, R., \& Harper, B. (2007). Learning Designs: Bridging the gap between theory and practice. In R. Atkinson, C. McBeath, S. K. A.. Soong \& C. Cheers (Eds.), Proceedings of the 24th Annual Conference of the Australasian Society for Computers in Learning in Tertiary Education (pp. 51-60). Singapore: ascilite.

Cross, S., Conole, G., Clark, P., Brasher, A., \& Weller, M. (2008). Mapping a landscape of Learning Design: Identifying key trends in current practice at the Open University. Paper presented at the 2008 European LAMS conference. 25-27 June, Cadiz, Spaine.

Donald, C., Blake, A., Girault, I., Datt, A. \& Ramsay, E. (2009). Approaches to learning design: past the head and the hands to the HEART of the matter. Distance Education, 30(2) 179-199.

Falconer, I., Beetham, H., Oliver, R., Lockyer, L., \& Littlejohn, A. (2007). Mod4L Final Report: Representing Learning Designs. Retrieved 14 May, 2008, from http://www.academy.gcal.ac.uk/mod41/

Goodyear, P., Salmon, G., Spector, M., Steeples, C., \& Tickner, S. (2001) Competencies of online teaching: A special report. Educational Technology Research and Development, 49(1), 65-72.

Hernández-Leo, D., Villasclaras-Fernández, E., Asensio-Pérez, J., Dimitriadis, Y., Iván M., RuizRequies, I., \& Rubia-Avi, B. (2006). COLLAGE: A collaborative Learning Design editor based on patterns. Educational Technology and Society, 9(1), 58-71.

Masterman, L. (2006). The Learning Design Tools Project Report: An evaluation of generic tools used in design for learning. Retrieved 26 August 2008, from http://www.jisc.ac.uk/uploaded_documents/LD\%20Tools\%20Report\%20v1.1.pdf

Stark, J. (2000). Planning introductory college courses: Content, context and form. Instructional Science, 28, 413-438. 